\title{
Editorial
}

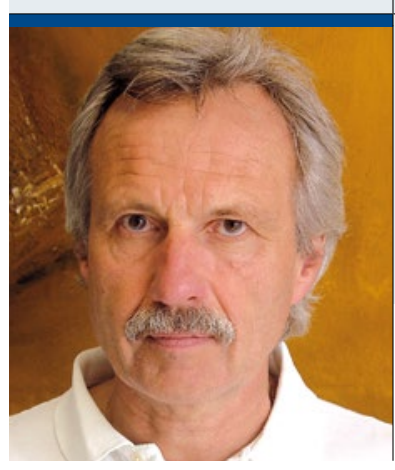

"Kunden von Versicherungen sollte nicht rauchen, nicht trinken, regelkonform Auto fahren - sich also kurzum prämiengerecht dressieren lassen."

\section{Big brothers are watching you}

$\mathrm{V}$ ersicherungskonzerne, allen voran Generali, wollen Online-Lebenspartner ihrer Kunden werden. So erfahren sie alles über deren Verhalten und Lebensweise und die daraus resultierenden Risiken. Mit den Versicherungsprämien kann das abgeleitete Risikoprofil honoriert oder bestraft werden. Bisher kalkulieren die Versicherer auf der Basis von Daten aus der Vergangenheit. Wesentlich aktueller und am Puls der Zeit sind die Daten, die bei Unternehmen wie Google, Amazon und vielen sozialen Netzwerken auflaufen. Sollten diese auf die Idee kommen, in das Versicherungsgeschäft einzusteigen, hätten die arrivierten Unternehmen einen potenziellen Informationsnachteil, der ihre Marktmacht empfindlich beeinträchtigen könnte. Schon jetzt geben die großen Unternehmen horrende Summen für die Gewinnung und Analyse von Daten aus.

Der einzelne Kunde wird sich auf Dauer nicht gegen das „Abmelken“ seiner Daten und Katalogisieren in Risikogruppen wehren können. Sind die durch versicherungskonformes Verhalten erzielbaren Beitragsreduktionen der Privatversicherungen gravierend genug, wird dies den Widerstand der Versicherungsnehmer gegen jede Form der Datenvereinnahmung brechen. Im Gegenzug werden die Beiträge für die Widerspenstigen sowie für die Alten und Kranken derart steigen, dass dies zur Willfährigkeit zwingt. Das heißt, die Versicherungskunden werden sich den Spielregeln der Versicherer beugen und sich den Fitnesscenterbesuch oder den gesunden Einkauf in den Partner-Supermärkten auf der Versichertenkarte bescheinigen lassen.

Den gesetzlichen Versicherungen steht noch das Solidaritätsprinzip im Weg. Aber das wird von ihnen bereits durch ein ausgeklügeltes Bonusprogramm ausgehöhlt. Die Bundesinnungskrankenkasse Gesundheit (BIG) bietet ihren Kunden als erste Direktkrankenkasse in Deutschland online einen umfangreichen Katalog an Boni an, die es für den als optimal definierten Body-Mass-Index, Blutdruck und Puls sowie für diverse Vorsorgemaßnahmen, den Nachweis sportlicher Aktivitäten und die Teilnahme an gesundheitsbezogenen Seminaren gibt.

Fazit: Kunden von Versicherungen sollte nicht rauchen, nicht trinken, regelkonform Auto fahren - sich also kurzum prämiengerecht dressieren lassen. Interessant wird es, wenn bei zukünftig autonomen Autofahrten die versicherungshörige Black Box mit dem Fahrstil des Computers in Zwist gerät und dies die Prämie erhöht. Der gebeutelte Fahrzeughalter ist gut beraten, den elektronischen Kunsthirnkasten nicht durch physische Gewalteinwirkung bestrafen zu wollen. Hierdurch erlittene Weichteilverletzungen könnten den Krankenkassenbeitrag steigern und einen psychologischen Test des renitenten Kunden nach sich ziehen.

\section{Schöne neue Welt}

Es ist bedrohlich, wenn Unternehmen Individualität stehlen und Lebewesen zu einer gleichgeschalteten, steuerbaren, beliebigen Normen und Ideologien folgenden Kohorte transformieren können. Normen und Ideologien werden von gewinnorientierten Unternehmen vorgegeben. Ob diese ethische, ehrbare oder verwerfliche Zielsetzungen verfolgen, ist kaum zu verifizieren. Im Zweifel sind sie nur der Rendite, dem „shareholder value“, oder welchen Unternehmenszielen auch immer zweckdienlich. Die Initiatoren verstecken sich hinter Gesellschaftsformen, die jede Verantwortlichkeit tarnen und vor dem Zugriff moralischer und vielleicht auch rechtlicher Instanzen schützen. Das bisherige Versicherungsprinzip der Absicherung des Einzelnen durch das Kollektiv wird gebrochen. Nur der Gesetzgeber ist in der Lage, diese uniforme Dressur zu beschneiden.

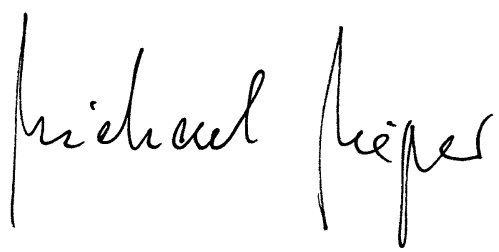

